\title{
SOCIAL ANALYTICS IN HEDONIC AND UTILITARIAN COMPANIES
}

\author{
Sarah Fischbach, New Mexico State University, United States
}

\begin{abstract}
Many consumers communicate through social media channels. A positive product review may be as persuasive as a welldesigned picture advertisement. Recent research suggests that advertisers should place more emphasis on pictures and visual components and less weight on verbal elements (McQuarrie \& Phillips, 2008). On the other hand, consumers, especially younger consumers, are reading product reviews, blogs, and other social media resources to gain information useful for making product decisions. Communications structured as narratives can be more persuasive than analytical presentations of product features (Escalas, 2007). Most consumers live in a world of narratives in which they encounter stories - and write their own stories - through there consumption patterns (Pacc, 2008). Students researched their own online communications in a YouTube video, "A Vision of a Student Today" (2007). They determined that in a single ycar the average college student wrote over 500 pages of emails through social media. What this student-conducted research revcals is the value of online resources. Refusing to utilize this information can place a company behind the curve by neglecting the next generation of consumers. The present study may assist managers as they attempt to create social media strategies.
\end{abstract}

This study was undertaken to examine the information content of social media analytical tools and to explore how this content differs for hedonic and utilitarian products. To date, no research has appeared examining social media analytic tools. This study, based on reader-tesponse theory, and using content analysis, focuses on these tools and recent trends in information content. These trends are compared across defined categories. The categories were established using an application of Resnik and Stern's (1977) work. The subjects of the analysis were two hedonic product companies and two utilitarian product companies, each of which uses three analytical tools. The social media analytic tools chosen for the study include: SM2, SocialMention and TrackUR. Several research questions have been explored and the findings present how managers can incorporate social media analytics in their business. The research questions addressed in the content analysis are: (1) Do the analytical tools capture communication though the 16 cues established in the codying scbeme? (2) What are the different information cues in hedonic and utilitarian products? (3) What are the differences between the monitoring tools and the information cues? (4) Through which online social media networks are consumers communicating for each of the product categories? (5) How can companies use these findings to set up and monitor their presence with social media tools?

This study produced a number of potentially useful insights, in part by including a content analysis to demonstrate the importance of social media tools in customer communication affairs. For utilitarian companies, a manager should focus on company sponsored research as well as provide links to such sites as twitter.com. Also, utilitarian companies would be well advised to the companies performances as well as their competitive advantage through social media. As for hedonic products, managers may wish to focus their socjal media efforts towards product endorsements, availability and quality of their products. Additionally, developing and keeping in touch with customers through a company blog may be beneficial to communication with the customer.

One concern of managers is how much effort can be expended on the observations and analysis of social media. Studies such as Morarity (2009) found that successful marketing campaigns can be conducted througly a series of whispers to individuals searching for what the firm has to offer. It is common knowledge that listening to what your consumers say (and where they are saying it) can help a company make decisions that add to their competitive advantage. This study presents only a fraction of the information available through social media. Overall, analyzing social media conversations can give managers another tool that they can use to better understand consumer needs and wants.

The findings in this study can be used as guidelines for establishing a social media marketing campaign. It is important to be in the conversation, regardless if the company markets utilitarian or hedonic products. Consumers convey information among each other and managers should be there to see what the target market members are seeking so that they can address their needs. In today's market, it is important to maintain a competitive advantage and create strategies to gain customer awareness. Of course, research on social media conversations is not a finite process. What is popular today may not be so a year from now, hence it is important to understand where the audience is going so the firm can evolve with them.

References Available Upon Recquest 